\title{
Photodynamics in Dentistry - A Review
}

\author{
Vasundhara Shivanna' Rucha Nilegaonkar ${ }^{2}$
}

Principal, Professor and Head' ${ }^{1}$ Post graduate student ${ }^{2}$

Department of Conservative Dentistry and Endodontics, College of Dental Sciences, Davangere

\section{Abstract:}

To overcome limitations of antibiotics like microbial resistance, systemic side effects and limitation of spectrum of microorganisms affected, an effective and alternative therapy needs to replace the conventional treatment. Photodynamic therapy (PDT) consists of a photoactive dye (photosensitizer) that is activated by specific wavelength light in the presence of oxygen. PDT has shown potential in the treatment of oral leukoplakia, oral lichen planus, and head and neck cancer, treatment of bacterial, fungal, parasitic, and viral infections. The absence of mutagenic effects of PDT is an important factor for safety during treatment.

Keywords: Oral biofilms, Photosensitizers, Photodynamic antimicrobial chemotherapy, Photodynamic therapy

\section{Introduction}

Photodynamic therapy (PDT) is a medical treatment that utilizes light to activate a photosensitizing agent (photosensitizer) in the presence of oxygen. The exposure of the photosensitizer to light results in the formation of oxygen species, such as singlet oxygen and free radicals, causing localized photodamage and cell death. Clinically, this reaction is cytotoxic and vasculotoxic. Depending on the type of agent, photosensitizers may be injected intravenously, ingested orally, or applied topically. The relative simplicity of the mechanism of activation of photosensitizers has stimulated considerable interest in PDT.

Currently, PDT is being applied mostly in the treatment of cancer, ${ }^{1-4}$ however, several studies have shown that PDT also has antimicrobial properties. ${ }^{5-12}$ Photodynamic antimicrobial chemotherapy (PACT) represents an alternative antibacterial, antifungal, and antiviral treatment for drug-resistant organisms. ${ }^{13}$ It is unlikely that bacteria would develop resistance to the cytotoxic action of singlet oxygen or free radicals. Applications of PDT in dentistry are growing rapidly: the treatment of oral cancer, as well as bacterial and fungal infections, and the photodynamic diagnosis (PDD) of the malignant

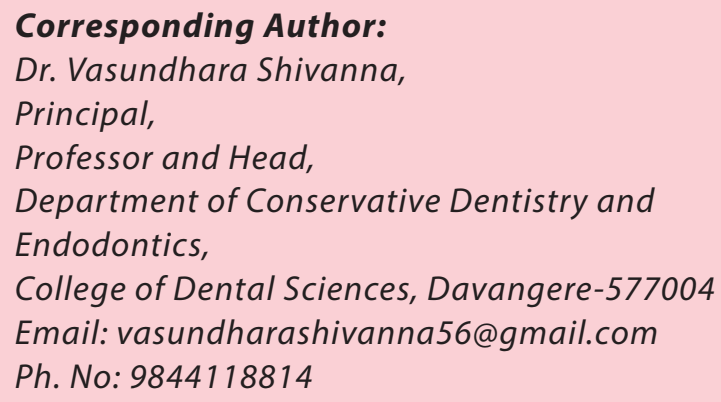

transformation of oral lesions. ${ }^{14}$ The non-oncological applications of PDT include treatment of psoriasis, ${ }^{15}$ actinic keratosis, ${ }^{16}$ rheumatoid arthritis, ${ }^{17}$ and age-related macular degeneration. ${ }^{18}$ The aim of this review is to outline the clinical results of PDT for the treatment of oral infections.

\section{Discussion Photodynamic reaction}

PDT involves three parts: incident light, a photosensitizer and oxygen. The light (photon) is absorbed by the photosensitizer, which undergoes a transition from a low energy ground state to an excited state. The activated photosensitizer interacts with oxygen to produce singlet oxygen and other free radical species that cause a toxic effect in tumor cells and microbial cells.

PDT produces cytotoxic effects through photodamage to subcellular organelles and molecules. Mitochondria, lysosomes, cell membranes, and nuclei of cells are considered potential targets, along with the tumor vasculature. During light exposure, sensitizers that localize in mitochondria may induce apoptosis, while sensitizers localized in lysosomes and cell membranes may cause necrosis. ${ }^{19}$

\section{Components of Photodynamic Therapy Light sources}

PDT requires a source of light that activates the photosensitizer by exposure to low-power visible light at a specific wavelength. Human tissue transmits red light efficiently, and the longer activation wavelength of the photosensitizer results in deeper light penetration. Consequently, most photosensitizers are activated by red 
light between 630 and $700 \mathrm{~nm} .{ }^{20,21}$ The total light dose, the dose rates, and the depth of destruction vary with each tissue treated and with each photosensitizer. ${ }^{2,22,23}$ At present, diode laser systems that are easy to handle, portable, and cost-effective are used predominantly. ${ }^{21}$ Recently, non-laser light sources, such as light-emitting diodes (LED), have also been applied in PDT. ${ }^{24-27}$

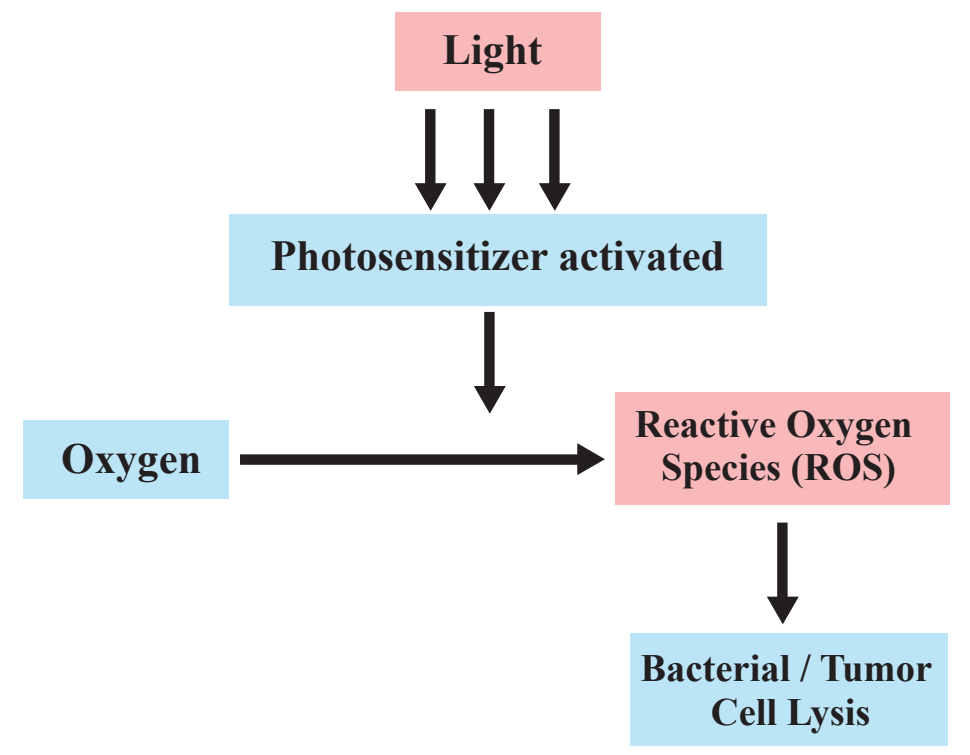

Fig. 1 Mechanism of action of Photodynamics (Courtesy: Konopka K, Goslinski T. Photodynamic Therapy in Dentistry. J Dent Res 2007; 86(8): 697)

\section{Photosensitizers}

Photosensitizers used in PACT include: (i) phenothiazine dyes [Methylene Blue (MB) and Toluidine Blue O (TBO; tolonium chloride)]; (ii) phthalocyanines [aluminum disulphonated phthalocyanine and cationic $\mathrm{Zn}$ (II)-phthalocyanine]; (iii) chlorines [chlorine6, Sn(IV)chlorine6, chlorine6-2.5 Nmethyl-d-glucamine (BLC1010)], and polylysine and polyethyleneimine conjugates of chlorine 6; (iv) porphyrins (hematoporphyrin $\mathrm{HCl}$, Photofrin, and ALA); (v) xanthenes (erythrosin); and (vi) monoterpene (azulene). The photosensitivity of bacteria appears to be related to the charge of the sensitizer. In general, neutral or anionic photosensitizers bind efficiently to and inactivate Gram positive bacteria. The affinity of negatively charged photosensitizers for Gram negative bacteria may be enhanced by linking the sensitizer to a cationic molecule (e.g., poly-L-lysine-chlorin e6), by the use of membrane-active agents (e.g., treatment with Tris-EDTA), or by conjugating the sensitizer with a monoclonal antibody that binds to cell-surface-specific antigens. ${ }^{5,6,10,28,29}$.

Photodynamic antimicrobial chemotherapy of dental and mucosal infections:
The oral cavity is colonized by complex, relatively specific, and highly interrelated micro-organisms, including aerobic and anaerobic Gram-positive and Gram-negative bacteria, fungi, mycoplasma, protozoa, and viruses. In the biofilm, bacteria exhibit increased resistance to antibiotics, environmental stresses, and host immune defense mechanisms. Two of the most common bacterial diseases that afflict humans are dental caries and periodontal diseases. Both result originally from a build-up of plaque biofilms on the teeth and soft tissues in the mouth.

\section{PDT in periodontal biofilms}

The antimicrobial activity of photosensitizers is mediated by singlet oxygen, which, because of its high chemical reactivity, has a direct effect on extracellular molecules. Thus, the polysaccharides present in extracellular matrix polymers of a bacterial biofilm are also susceptible to photodamage. Such dual activity, not exhibited by antibiotics, represents a significant advantage of PACT. Electron microscopy and confocal microscopy have revealed destruction of periodontal biofilms by $\mathrm{Zn}(\mathrm{II})-$ phthalocyanine ${ }^{29}$ and poly-L-lysine-chlorine 6 conjugate (pLCe6). ${ }^{30}$. Studies on multispecies biofilms and Streptococcus mutans have shown to kill bacteria subjected to PACT. ${ }^{31}$. 


\section{PDT in Endodontics}

Various studies done on Streptococcus intermedium have shown to reduce the number of these microorganisms from infected root canals. ${ }^{32,33}$ Some studies done on Enterococcus faealis showed that PACT was effective in killing these organisms beyond $95 \%$. 34,35 while other studies revealed $77.5 \%$ reduction in E. faecalis viability. ${ }^{36}$ Biofilms of Proteus mirabilis and Pseudomonas aeruginosa, prepared in extracted human teeth, were treated using PACT. PACT alone reduced the bacterial load by $95 \%$, while the combination of standard endodontic treatment with PACT reduced it by $>98 \%$. ${ }^{37}$

Results of certain studies suggest that the use of PDT as an adjuvant to the conventional endodontic treatment leads to a statistically significant further reduction of bacterial load and in particular reduces the amount of bacterial regrowth after 24 hours compared to either treatment alone. ${ }^{38,39}$ Data from an ex vivo study indicated that PDT significantly reduces residual bacteria within the root canal system, and that PDT, if further enhanced by technical improvements, holds substantial promise as an adjunct to chemomechanical debridement. ${ }^{40}$

\section{PDT in Peri-implantitis}

Peri-implantitis is a multifactorial process involving bacterial contamination of the implant surface and the formation of biofilms. Bacterial plaque on implants leads to inflammatory changes in the adjacent soft tissues. In vitro studies done to check the effect of Toluidine Blue $\mathrm{O}$ (TBO) on Actinobacillus actinomycetemcomitans, Porphyromonas gingivalis, and Prevotella intermedia in peri-implantitis cases revealed a significant reduction in their numbers. ${ }^{41,42}$ In vivo animal experiments showed that bacterial load and alveolar bone loss could significantly reduced in peri-implantitis cases. ${ }^{43}$ PACT was conducted with two sensitizers, chlorine 6 and a novel water-soluble chlorine 6 derivative, BLC1010, followed by illumination with a diode laser $(662 \mathrm{~nm}){ }^{44}$ The treatment caused a significant reduction in redness and bleeding on probing; Porphyromonas gingivalis was much more sensitive to PACT than was Fusobacterium nucleatum.

\section{PDT in Candidial infections}

Oropharyngeal candidiasis, caused by Candida albicans is a widespread opportunistic infection in HIV-infected individuals and in patients taking immunosuppressive drugs.
Candida-associated denture stomatitis is a common recurrent disease in denture wearers. The ability of Candida albicans to form biofilms on epithelial surfaces and prosthetic devices contributes to the failure of antifungal therapy and to recurrent infections. ${ }^{45}$ The increasing resistance of Candida albicans to antifungal agents has stimulated an interest in the new treatments. Like other yeasts, Candida albicans is more difficult to kill by PACT than are Gram-positive bacteria. This is attributed to the presence of a nuclear membrane and the larger cell size. ${ }^{46}$ Experiments on mucoadhesive patches containing TBO as a potential delivery system in oral candidiasis were done using a Paterson lamp $(635 \mathrm{~nm})$. Significant reduction of the candidial cells was seen. ${ }^{12}$ In immunosuppressed mice, topical application of Methylene Blue (MB) at 450 and 500 $\mathrm{g} / \mathrm{mL}$, followed by illumination with a diode laser (664 $\mathrm{nm}$ ), totally eradicated Candida albicans from pseudomembranous candidiasis lesions on the dorsum of the tongue. ${ }^{47}$

\section{Tumors and Malignancies}

Oral squamous cell carcinoma (SCC) is the most frequent malignant tumor of the oral cavity and the eighth most common cancer in the world, representing $2-4 \%$ of annually diagnosed cancers. ${ }^{48}$ Despite numerous advances in surgery, chemotherapy, and radiation, the five-year survival rate has not improved significantly over the last 50 years. These conventional treatments cause many side effects, including jaw pain, mouth sores, dysfunctional salivary glands, and difficulties in chewing, swallowing, and talking. ${ }^{49}$ The advantage of PDT over conventional treatments is based on its minimal invasiveness and relatively selective tumor destruction, with the preservation of healthy tissues. These features of PDT are important for head and neck SCC, in which excessive tissue loss causes considerable functional problems. In addition, PDT may be applied in combination with conventional treatments. ${ }^{2}$ Clinical applications and outcomes of PDT in the treatment of head and neck SCC have been reviewed. ${ }^{2,3,23}$ In various studies done till now, patients having different types of cancerous lesions, including primary, recurrent, and metastatic lesions have been studied. The prevalent histology was SCC, but others included mucosal melanoma, Kaposi's sarcoma, adeno - carcinoma, metastatic breast carcinoma, and adenoid cystic carcinoma have responded to PDT from a range of $100 \%{ }^{50}$ to $40 \%$ recovery. ${ }^{51}$ 
The clinical simplicity of drug-, light-, and oxygen-based reaction has stimulated the current expansion of PDT. Yet even the best currently available systemic photosensitizers accumulate to a certain degree in other organs, particularly in the skin, causing prolonged photosensitivity after exposure to light. The lack of accurate dosimetry, combined with insufficiently defined treatment parameters, has also diminished the success of PDT. ${ }^{24}$ Although PDT was originally considered as a local treatment, limited to sites where the light activates a photosensitizer, it is now realized that PDT can initiate regional and systemic immune responses. ${ }^{52}$ Despite all these limitations, the existing photosensitizers and light sources have achieved significant clinical success, allowing PDT to expand. The development of optimal photosensitizers should address the problems of toxicity, mutagenicity, and elimination of the drug from the patient, selectivity and target ability of photosensitizers, dependable activation by an appropriate wavelength of light, sunlight precautions, simplicity of administration, pain-free outpatient therapy, availability, and cost-effectiveness.

\section{Conclusion}

PDT seems to be an effective tool in the treatment of localized and superficial infections. Oral infections such as mucosal and endodontic infections, periodontal diseases and peri-implantitis are among the specific targets where PDT can be applied. Further long-term clinical studies are necessary in establishing a more specific place of the technique in the field of dentistry.

\section{References}

1. Hopper C. Photodynamic Therapy: a clinical reality in treatment of cancer. Lancet Oncol 2000; 1: 212-219.

2. Biel M. Photodynamic therapy in head and neck cancer. Curr Oncol Rep 2002; 4: 87-96.

3. Biel M. Advances in photodynamic therapy for treatment of head and neck cancers.Lasers Surg Med 2006; 38: 349-355.

4. Allison. Clinical PD/PDT in North America: a historical review. Photodiagn Photodyn Ther 2004c; 1: 263-277.

5. Wainwright M. Photodynamic antimicrobial chemotherapy (PACT). J Antimicrob Chemother 42:13-28.
6. Hamblin MR and Hasan T. Photodynamic therapy: a new antimicrobial approach to infectious disease? Photochem Photobiol Sci 2004; 3: 436-450.

7. Meisel P, Kocher T. Photodynamic therapy for periodontal diseases: state of the art. J Photochem Photobiol B 2005; 79:159-170.

8. O'Riordan, K., Akilov, O., and Hasan, T. The potential for photodynamic therapy in the treatment of localized infections. Photodiagn Photodyn Ther $2005 ; 2: 247-262$.

9. Smith. Biofilms and antibiotic therapy: is there a role for combating bacterial resistance by use of novel drug delivery systems? Adv Drug Deliv Rev 2005; 57:1539-1550.

10.Kömerik MR. Photodynamic therapy as an alternative antimicrobial modality for oral infections. J Environ Pathol Toxicol Oncol 2006; 25:487-504.

11. Wood S, Metcalf D, Devine D, Robinson C. Erythrosine is a potential photosensitizer for the photodynamic therapy of oral plaque biofilms. J Antimicrob Chemother 2006; 57:680-684.

12.Donnelly. Potential of photodynamic therapy in treatment of fungal infections of the mouth. Design and characteristics of a mucoadhesive patch containing toulidine blue O. J Photochem Photobiol B 2007; 86:59-69.

13. Wainwright, Crossley. Photosensitizing agents circumventing resistance and breaking down biofilms: a review. Int Biodererior Biodegrad 2004; 53:119-126.

14.Sharwani. Fluorescence spectroscopy combined with 5 -aminolevulinic acid-induced protoporphyrin IX fluorescence in detecting oral premalignancy. J Photochem Photobiol B 2006; 83:27-33.

15.Weinstein. Low dose Photofrin II photodynamic therapy of psoriasis. J Invest Dermatol 1991; 96(Suppl): 573-578.

16.Itoh. Topical delta-amivolevuliniv acid-based photodynamic therapy for Japanese actinic keratoses. J Dermatol 2000; 27:513-518.

17.Miyazawa S, Nishida K, Komiyama T, Nakae Y, Tadeda K, Yorimitsu $\mathrm{M}$ et al. Novel transdermal photodynamic therapy using ATX-S10.Na(II) induces apotosis of synovial fibroblasts and ameliorates collagen antibody-induced arthritis in mice. Rheumatol Int 2006; 26:717-725. 
18.Kozak I, Cheng L, Cochran DE, Freeman WR. Phase I clinical trial results of verteporfin enhanced feeder vessel therapy in subfoveal choroidal neovascularisation in age related macular degeneration. Br J Ophthalmol 2006; 90:1152-1156.

19.Castano. Mechanisms in photodynamic therapy: part two - cellular signaling, cell metabolism and modes of cell death. Photodiagn Photodyn Ther 2005; $2: 1-23$.

20.Salva. Photodynamic therapy: unapproved uses, dosages, or indications. Clin Dermatol 2002; 20:571-581.

21.Kübler. Photodynamic therapy. Med Laser Appl $2005 ; 20: 37-45$.

22.Grant WE, Speight PM, Hopper C, Bown SG. Photodynamic therapy: an effective, but non-selective treatment for superficial cancers of the oral cavity. Int J Cancer 1997; 71:937-942.

23.Allison RR, Cuenca RE, Downie GH, Camnitz P, Brodish B, Sibata CH. Clinical photodynamic therapy of head and neck cancers - a review of applications and outcomes. Photodiagn Photodyn Ther 2005; 2:205-222.

24.Allison RR, Baganto VS, Cuenca R, Downie GH, Sibata $\mathrm{CH}$. The future of photodynamic therapy in oncology. Future Oncol 2006; 2:53-71.

25.Juzeniene A, Juzenas P, iani V, Moan J. Effectiveness of different light sources for 5-aminolevulinic acid photodynamic therapy. Lasers Med Sci 2004; 19:139-149.

26.Pieslinger. Characterization of a simple and homogenous irradiation device based on light-emitting diodes: a possible low-cost supplement to conventional light sources for photodynamic treatment. Med Laser Appl 2006; 21:277-283.

27.Steiner. New laser technology and future applications. Med Laser Appl 2006; 21:131-140.

28.Rovaldi CR, Pievsky A, Sole NA, Friden PM, Rothstein DM, Spacciapoli P. Photoactive porphyrin derivative with broad-spectrum activity against oral pathogens in vitro. Antimicrob Agents Chemother 2000; 44:3364-3367.

29. Wood. An in vitro study of the use of photodynamic therapy for the treatment of natural oral plaque biofilms formed in vivo. J Photochem Photobiol B 1999; 50:1-7.

30.Soukos NS, Mulholland SE, Socransky SS, Doukas AG. Photodestruction of human dental plaque bacteria: enhancement of the photodynamic effect by photomechanical waves in an oral biofilm model.
Lasers Surg Med 2003; 33:161-168.

31.O'Neill JF, Hope CK, Wilson M. Oral bacteria in multi-species biofilms can be killed by red light in the presence of toluidine blue. Lasers Surg Med 2002; 31:86-90.

32.Williams JA, Pearson GJ, Colles MJ. Antibacterial action of photoactivated disinfection $\{\mathrm{PAD}\}$ used on endodontic bacteria in planktonic suspension and in artificial and human root canals. J Dent 2006; 34:363-371.

33.Seal GJ, Ng YL, Spratt D, Bhatti M, Gulabivala K. An in vitro comparison of the bactericidal efficacy of lethal photosensitization or sodium hypochlorite irrigation on Streptococcus intermedius biofilms in root canals. Int Endod J 2002; 35:268-274.

34.Rocas IN, Siqueira JF Jr, Santos KR. Association of Enterococcus faecalis with different forms of periradicular diseases. J Endod 2004; 30: 315-320.

35.Soukos NS, Shen PS, Morris JT. Photodynamic therapy for endodontic disinfection. J Endod 2006; 32:979-984.

36.Foschi F, Fontana CR, Ruggiero K, Riahi R, Vera A, Doukas A et al. Photodynamic inactivation of Enterococcus faecalis in dental root canals in vitro. Lasers Surg Med 2007; 39:782-787.

37.Garcez AS, Ribeiro MS, Tegos GP, Nunez SC, Jorge AO, Hamblin MR. Antimicrobial photodynamic therapy combined with conventional endodontic treatment to eliminate root canal biofilm infection. Lasers Surg Med 2007; 39:59-66.

38.Garcez AS, Nunez SC, Hamblin MR, Ribeiro MS. Antimicrobial Effects of Photodynamic Therapy on Patients with Necrotic Pulps and Periapical Lesion. J Endod. 2008 February; 34(2): 138-142.

39. Hayek RRA, Araujo NS, Gioso MA, Ferreira J, Baptista-Sobrinho CA, Yamada JR AM et al. Lasers Surg Med. 2007 January; 39(1): 59-66.

40.Raymond NG, Singh F, Papamanou DA, Song X, Patel C, Holewa C, et al. Endodontic photodynamic therapy ex vivo. J Endod. 2011 February; 37(2): $217-222$.

41.Dörtbudak O, Haas R, Bernhart T, Mailath-Pokorny, G. Lethal photosensitization for decontamination of implant surfaces in the treatment of peri-implantitis. Clin Oral Implants Res 2001; 12:104-108.

42.Haas R, Baron M, Dortbudak O, Watzek G. Lethal photosensitization, autogenous bone, and e-PTFE membrane for the treatment of peri-implantitis: preliminary results. Int $\mathrm{J}$ Oral Maxillofac Implants 2000; $15: 374-382$. 
43.Kömerik N, Nakanishi H, MacRobert AJ, Henderson $B$, Speight $\mathrm{P}$, Wilson $\mathrm{M}$. In vivo killing of Porphyromonas gingivalis by toluidine blue-mediated photosensitization in an animal model. Antimicrob Agents Chemother 2003; 47:932-940.

44.Sigusch BW, Pfitzner A, Albrecht V, Glockmann E. Efficacy of photodynamic therapy on inflammatory signs and two selected periodontopathogenic species in a beagle dog model. J Periodontol 2005; 76:1100-1105.

45.Douglas. Candida biofilms and their role in infection. Trends Microbiol 2003; 11:30-36.

46.Demidova and Hamblin. Effect of cell-photosensitizer binding and cell density on microbial photoinactivation. Antimicrob Agents Chemother 2005; 49:2329-2335.

47.Teichert. Treatment of oral candidiasis with methylene blue-mediated photodynamic therapy in an immunodeficient murine model. Oral Surg Oral Med Oral Pathol Oral Radiol Endod 2002; 93:155-160.
48.Massano J, Regateiro FS, Januario G, Ferreira A. Oral squamous cell carcinoma: review of prognostic and predictive factors. Oral Surg Oral Med Oral Pathol Oral Radiol Endod 2006; 102:67-76.

49.Silverman. Oral cancer: complications of therapy. Oral Surg Oral Med Oral Pathol Oral Radiol Endod 1999; 88:122-126.

50.Schuller. Photodynamic therapy in head and neck cancer. Arch Otolaryngol 1985; 111:351-355.

51.Edge and Carruth. Photodynamic therapy and the treatment of head and neck cancer. $\mathrm{Br} \mathrm{J}$ Oral Maxillofac Surg 1988; 26:1-11.

52.Dougherty TJ, Gomer CJ, Henderson BW, Jori G, Kessek D, Korbelik M et al. Photodynamic therapy. J Natl Cancer Inst1998; 90:889-905.

How to cite this article:

Shivanna V, Nilegaonkar R. Photodynamics in Dentistry -

A Review. CODS J Dent 2015;7: 13 - 18

Source of support: Nil. Conflict of interest: None Declared. 